Original article

\title{
HISTOSTRUCTURE OF DIFFERENT QUALITY CLASSES OF FATTENED LIVER FROM MULE DUCKS
}

\author{
P. PETROV ${ }^{1}$, A. BOCHUKOV ${ }^{1}$, G. PENCHEV ${ }^{2} \&$ V. GERZILOV ${ }^{1}$
}

${ }^{1}$ Department of Animal Science, Faculty of Agronomy, Agricultural University, Plovdiv, Bulgaria; ${ }^{2}$ Department of Veterinary Anatomy, Histology and Embryology, Faculty of Veterinary Medicine, Trakia University, Stara Zagora, Bulgaria

\section{Summary}

Petrov, P., A. Bochukov, G. Penchev \& V. Gerzilov, 2017. Histostructure of different quality classes of fattened liver from mule ducks. Bulg. J. Vet. Med., 20, No 4, 319-326.

This study encompassed a total of 15040 fattened liver samples, obtained during the four seasons of the year. The fattened liver quality was evaluated with regard to its weight and structure and classified in five classes. The analysis of the results indicated that the largest amount of fattened liver from the two highest quality classes - "Esc" and "E" was obtained during the autumn ( $85.46 \%$ total), whereas in the other seasons the largest amounts of fattened liver were of the "AD" class. The spring was a period when an increase in the relative share of low-quality liver of grade "TV" $(20.87 \%)$ and "C" $(5.07 \%)$ was detected. The histological studies indicated that hepatocytes with large-drop fatty infiltration were predominant in liver of classes "Esc" and "E", with preserved cellular boundaries, with the exception of sporadic cases in the "Esc" class, mostly in the autumn. A specific feature for the "AD" quality class was the prevalence of glandular tubules, with predominantly small- and mediumdrop fatty infiltration occurring within their hepatocytes. Seasonal differences in the histostructure of the fattened liver were also detected. In the "TV" quality class two types of glandular tubules with small- and medium-drop fatty infiltration were observed. In some cases, large-drop fatty infiltration could be observed as well - mostly in the summer, and connective tissue between the glandular tubules was preserved, without fattening of its cells. In the " $\mathrm{C}$ " quality class, fatty infiltration was incomplete. The histological image showed mostly small-drop fatty infiltration in the cytoplasm of most hepatocytes.

Key words: fatty liver, force feeding, histology, mule duck, qualification

\section{INTRODUCTION}

Duck breeding has been strongly present in Bulgaria and it makes up over $20 \%$ of the total poultry production and over $80 \%$ of the total export of poultry products. Even though there is no tradition for the consumption of the delicacy known as ,foie gras" in our country, its production increases continuously. Currently, Bulgaria and Hungary have the largest production after the global leader - France. In 2014, the produced fattened liver in Bulgaria amounted to 2,962 t (Anonymous, 
2015). The structure and taste qualities of the fattened liver make it a festive (gourmet) food, with consumer demand in some countries.

While force feeding mule ducks, producers aim to achieving fattened liver with a mass of 500-700 g. The production of a small liver is related to an insufficient extent of fatty infiltration of the hepatocytes, whereas the production of a too large liver bears the risk of disrupting the integrity of liver cells and accumulation of fat in the intercellular areas. This, in turn, leads to the liver's increased capacity for melting, which is related to loss of fats, i.e. reduction of the technological yield or its quality (Rousselot-Pailley et al., 1992). According to Theron et al. (2012) the excessively heavy liver correlates negatively with technological yields.

Most authors believe that a period of 12-14 days is the most optimal for achieving a high-quality fattened liver with a low extent of disrupted hepatocyte integrity (Baudonnet-Lenfant, 1993; Gabarrou et al. 1996; Guy et al., 1999; Theron et al., 2012; Gontier et al., 2013; Bonnefont et al., 2015).

The goal of the present study was to describe the histostructure of the fattened liver depending on its quality and the season it was produced in.

\section{MATERIALS AND METHODS}

The study was conducted at the Bullion poultry slaughterhouse in the town of Parvomay. A total of 15,040 pieces of fattened liver were obtained from mule ducks force-fed by 6 farmers for a duration of 13 days (from the age of 75 to 87 days) with steamed corn. The following amounts of liver were produced and categorised in each season of the year: in the spring - 3,651 pcs.; in the summer 3,716 pcs.; in the fall $-3,706$ pcs.; in the winter $-3,967$ pcs.

The fattened liver was categorised by qualified staff, depending on its weight and structure, as follows (Fig. 1):
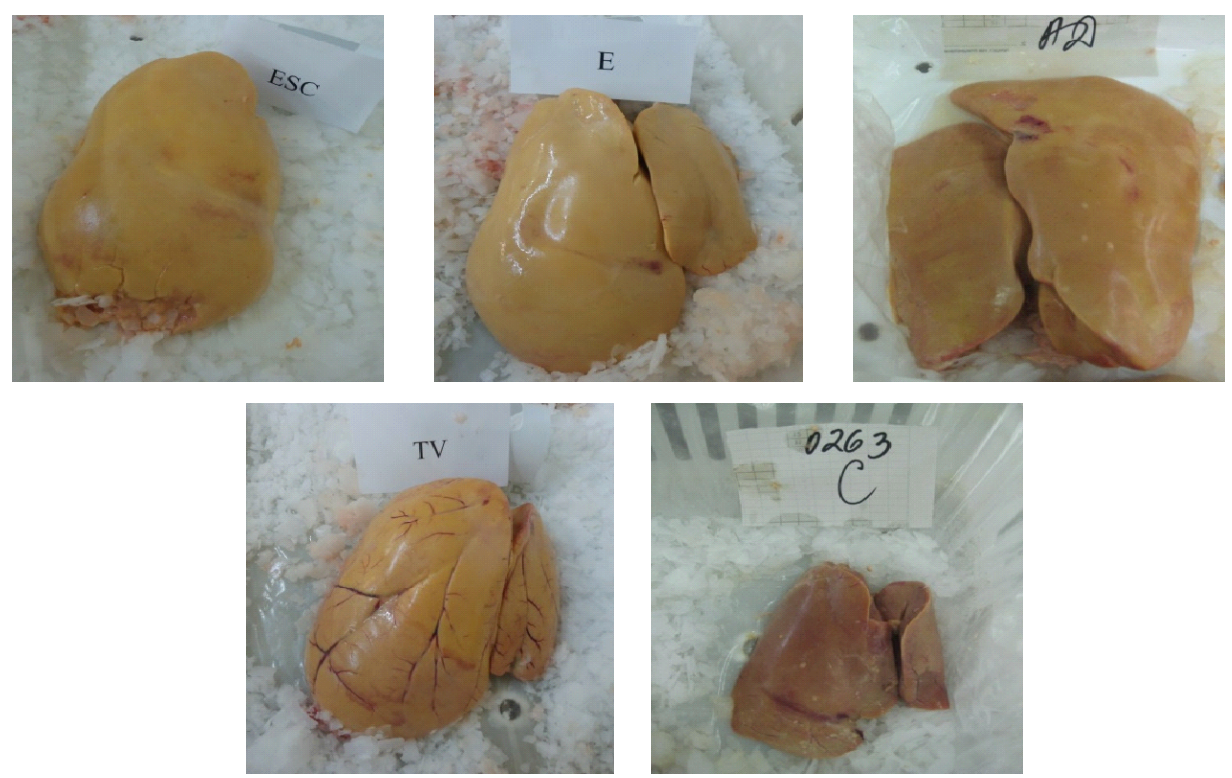

Fig. 1. Appearance of mule duck fattened liver from the different studied classes. 
- Class „Esc” - extra quality liver over $700 \mathrm{~g}$, homogeneous pale yellow colour, no haematomas, no lesions;

- Class „E” - 500-600 g with good outer appearance, homogeneous pale yellow colour, no haematomas, no lesions;

- Class „AD” - from 300 to $700 \mathrm{~g}$ with good appearance, homogeneous pale yellow colour, small haematomas, no lesions;

- Class „TV” - over $300 \mathrm{~g}$ with strongly pronounced veins, with haematomas, soft consistency;

- Class „C” - liver below $300 \mathrm{~g}$.

Along with the categorisation of each liver, 25 samples from each quality class for every season were collected from the right lobe of the parietal surface (pieces $0.7 \times 0.7 \times 0.7 \mathrm{~cm}$ of size) for histological study. In order to compare the histological image before and after force feeding, liver samples were obtained before the start of the ducks' force feeding as well.

The liver pieces were fixed in fresh Bouin's solution for $72 \mathrm{~h}$. Then the fixative was removed in ascending alcohol series $(60,70 \%, 80 \%, 90 \%, 96 \%$ ethanol and two times in absolute ethanol at room temperature for $30 \mathrm{~min}$ each), specimens were cleared in xylene, embedded in paraffin, cut on a Reichert microtome. Sections $6 \mu \mathrm{m}$ thick were mounted on glass slides and stained with haematoxylineosin. Histological examinations were performed with Jenaval light microscope, and findings were documented with a camera (CETI, Belgium).

The results are presented as mean \pm SEM. Statistical processing of data was done using Student's $t$-test (StatMost for Windows) and the differences were considered significant at $\mathrm{P}<0.05$.

Table 1. Yield of mule duck fattened liver from the different quality classes according to the seasons. Liver weight is presented as mean \pm SEM

\begin{tabular}{|c|c|c|c|c|c|c|}
\hline & \multicolumn{6}{|c|}{ Class of fatty liver } \\
\hline & Esc & $\mathrm{E}$ & $\mathrm{AD}$ & TV & $\mathrm{C}$ & waste \\
\hline \multicolumn{7}{|l|}{ Spring $(n=3651)$} \\
\hline Number of samples & 213 & 1110 & 1334 & 762 & 185 & 47 \\
\hline Liver weight (g) & $743 \pm 3.12$ & $584 \pm 1.59$ & $423 \pm 1.59$ & $491 \pm 3.87$ & $257 \pm 2.24$ & - \\
\hline Total yield \% & 5.83 & 30.40 & 36.54 & 20.87 & 5.07 & 1.29 \\
\hline \multicolumn{7}{|l|}{ Summer $(n=3716)$} \\
\hline Number of samples & 447 & 1127 & 1599 & 486 & 52 & 5 \\
\hline Liver weight (g) & $762 \pm 2.48$ & $624 \pm 1.26$ & $466 \pm 1.60$ & $522 \pm 4.74$ & $266 \pm 4.61$ & - \\
\hline Total yield $\%$ & 12.03 & 30.33 & 43.03 & 13.08 & 1.40 & 0.13 \\
\hline \multicolumn{7}{|l|}{ Autumn $(n=3706)$} \\
\hline Number of samples & 1054 & 2113 & 122 & 369 & 30 & 18 \\
\hline Liver weight (g) & $784 \pm 2.36$ & $575 \pm 1.70$ & $369 \pm 4.19$ & $560 \pm 5.91$ & $252 \pm 5.49$ & - \\
\hline Total yield \% & 28.44 & 57.02 & 3.29 & 9.96 & 0.81 & 0.49 \\
\hline \multicolumn{7}{|l|}{ Winter $(n=3967)$} \\
\hline Number of samples & 522 & 1344 & 1500 & 542 & 51 & 8 \\
\hline Liver weight (g) & $761 \pm 2.71$ & $608 \pm 1.49$ & $452 \pm 1.73$ & $492 \pm 4.21$ & $267 \pm 7.36$ & - \\
\hline Total yield $\%$ & 13.16 & 33.88 & 37.81 & 13.66 & 1.29 & 0.20 \\
\hline
\end{tabular}

BJVM, 20, No 4 


\section{RESULTS}

The results (Table 1) indicated that the largest amount of fattened liver from the two highest classes - "Esc" and "E" was produced in the autumn $(85.46 \%$ total). The sum of their percentages varied from $81.57 \%$ to $90.16 \%$ for the different growers. Throughout the other three seasons, the yield of fattened liver from the two highest classes was, respectively, $47.04 \%$ in the winter, $42.36 \%$ in the summer and $36.23 \%$ in the spring.

The yield of "AD" class fattened liver was the lowest in the fall $-3.29 \%$. This made sense, considering that these three liver classes are partially overlapping with regard to weight, yet unlike the "Esc" and "E" classes, haematomas are observed in the "AD" class.

In the spring, the relative share of the produced fattened liver of the "TV" class (of low quality and price), was the highest $(20.87 \%)$. The same was true for " $\mathrm{C}$ " class liver, which denotes the lowest quality.

The histological study showed that hepatocytes (Epitheliocytus hepatis) were the predominant cell type in the unfattened liver, forming the specific glandular tubules. They were radiating from the centrally positioned within the glandular lobes $v$. centralis. The lumen of longitudinally cut tubules was separated by two lines of hepatocytes. The longitudinal cuts of the tubules revealed that their walls were built up by 5 to 6 hepatocytes: relatively larger polygonal cells with acidophilic cytoplasm and one spherical basophilic nucleus. Among the glandular tubules the relatively wide sinusoidal capillaries, which ended in the central vein of the liver lobe were observed. The latter were not well-defined morphologically due to the low content of loose connective tissue in the interlobular spaces. Such tissue was located only in the zone of the interlobular vessels - arteries, veins and gall canals (Fig. 2).

Large fatty drops predominated within the cytoplasm of hepatocytes of "Esc" quality class livers (Fig. 3). Single cases of cytoplasm membrane ruptures, related to an increase in liver melting point were observed, mostly during the autumn. During the summer and, to an extent, in the spring, the histological examinations of the liver indicated that a part of the hepatocytes exhibited small-drop fatty infiltration - an indication of insufficient utilisation of the liver cells' cytoplasm potential with respect to fatty droplets content. This would eventually lead to lower fatty liver yields in the summer period and a relatively smaller share of "Esc" class liver for these two seasons.

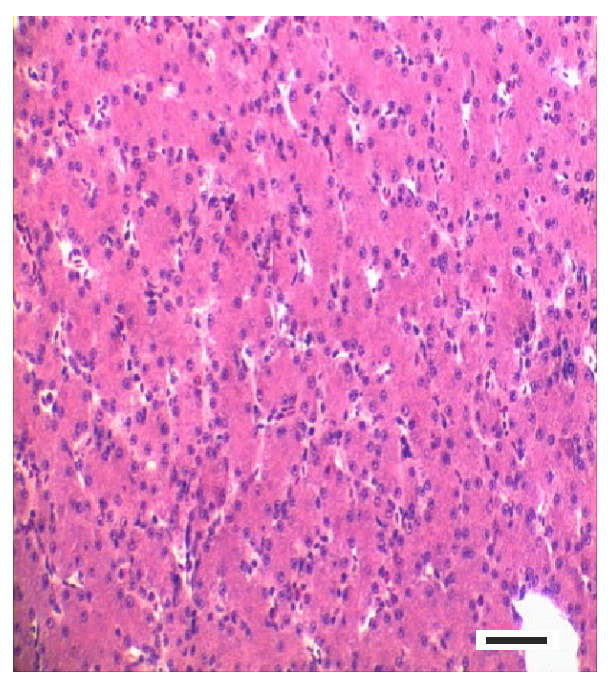

Fig. 2. Liver before force-feeding (74-day-old), H/E, bar=100 $\mu \mathrm{m}$.

In the "E" quality class, the predominant hepatocytes exhibited large-drop fatty infiltration. Nevertheless, the cellular boundaries remained preserved, and the shape of their nuclei was spherical. It was only during the winter period that medium-drop fatty infiltration of the hepato- 
cytes was predominant in some of the samples. In this quality class, the presence of extracellular fat was observed only in isolated cases. In general, the integrity of the cell membranes was preserved here as well, leading to liver with a low extent of melting (Fig. 4). It was only during the winter period that medium-drop fatty infiltration of the hepatocytes was predominant in single the histological samples.

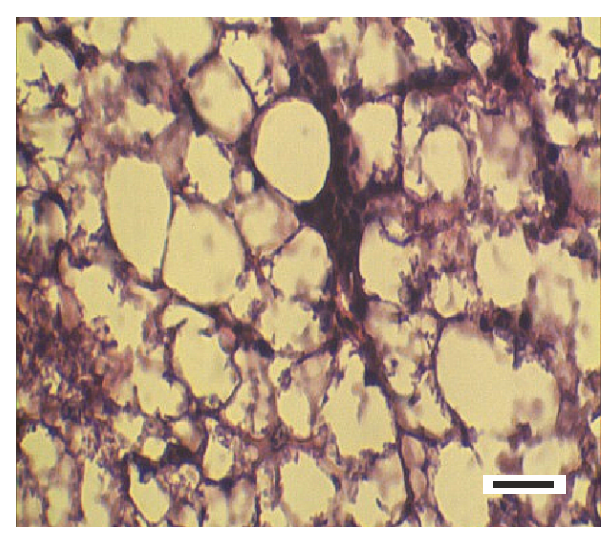

Fig. 3. Liver class ,Esc” after force-feeding. $\mathrm{H} / \mathrm{E}, \mathrm{bar}=100 \mu \mathrm{m}$.

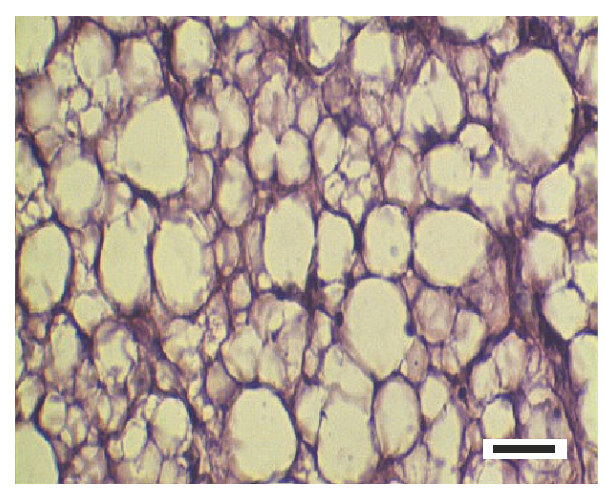

Fig. 4. Liver class ,, $E$ “ after force-feeding. $\mathrm{H} / \mathrm{E}$, bar $=100 \mu \mathrm{m}$.

Within the parenchyma of the "AD" class liver (Fig. 5) glandular tubules with hepatocytes exhibiting small- and medium-drop fatty infiltration, were predomi- nant. The presence of single large fat drops was observed only in some hepatocytes. During the spring, an approximately identical state of the liver parenchyma could be observed - the presence of medium and large fat drops in the hepatocytic cytoplasm. During the summer, the hepatocytes exhibited mostly small-drop fatty infiltration. During the autumn season, the hepatocytes in the three groups were relatively small in size. During the winter period, the histological image showed a nearly identical presence of small and average-sized fat drops in the hepatocytes' cytoplasm.

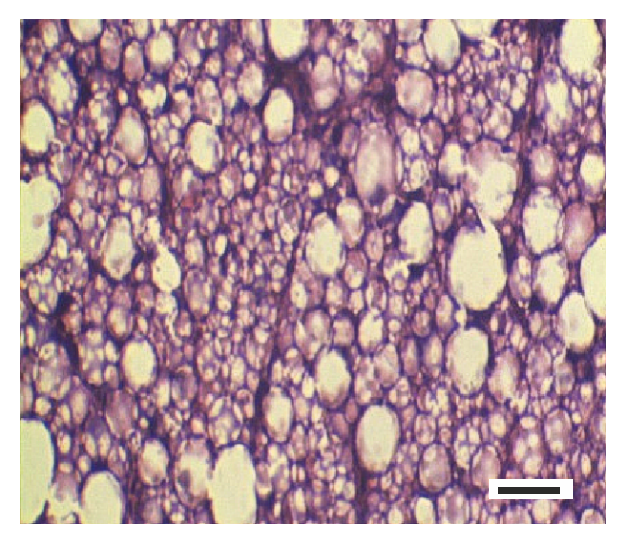

Fig. 5. Liver class „AD” after force-feeding. $\mathrm{H} / \mathrm{E}$, bar $=100 \mu \mathrm{m}$

An intriguing and varied histological image was observed in fattened livers of the "TV" quality class (Fig. 6). The hepatocytes of a major portion of the glandular tubules had small- and average-drop fatty infiltration in their cytoplasm. The nuclei were small, spherical and with densely stained chromatin. The connective tissue between the glandular tubules was preserved without fattening of its cells. Large fat drops were observed in the cytoplasm of some of the hepatocytes, while the cellular boundaries were preserved. During the fall there was an approximately equal 
presence of medium and large fat drops in the cytoplasm of liver cells, while the presence of small fat drops was predominant in the winter.

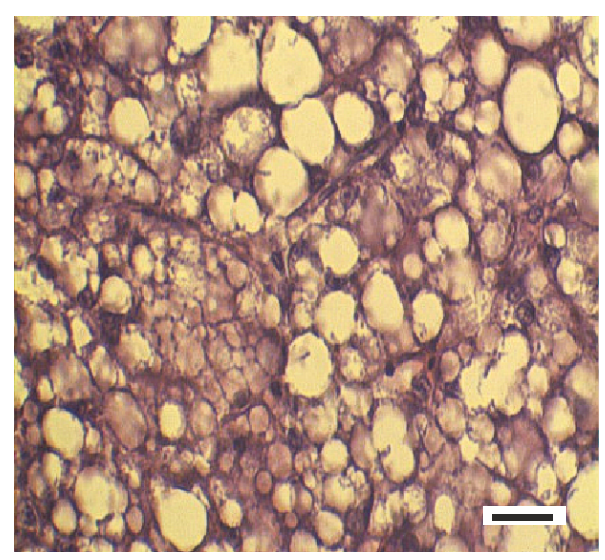

Fig. 6. Liver class „TV”, after force-feeding. $\mathrm{H} / \mathrm{E}, \mathrm{bar}=100 \mu \mathrm{m}$.

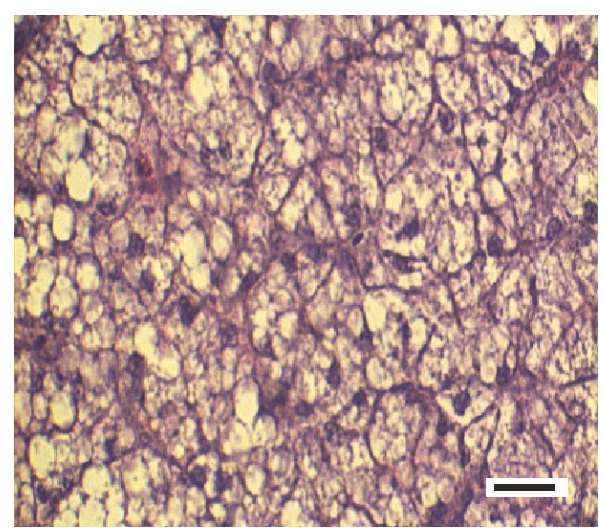

Fig. 7. Liver class „C”, after force-feeding. $\mathrm{H} / \mathrm{E}, \mathrm{bar}=100 \mu \mathrm{m}$.

For the livers of the "C" (Fig. 7) quality class, incomplete fatty infiltration of the hepatocytes was observed. There was primarily small-drop fatty infiltration in the cytoplasm of most hepatocytes. The general impression was that their full potential had not been fulfilled with regard to fat drop content. Medium to large hepatocytes with preserved cellular boundaries were observed, although rarely. The hepatocytes' nuclei did not change their positions, they were spherical, preserved, without any signs of nuclear degeneration. The shapes of the glandular tubules and the considerably narrowed intervenous sinusoidal blood vessels were relatively clear. No seasonal differences in the liver's histostructure were found.

\section{DISCUSSION}

The achieved results indicated that the largest amount of fattened liver from the two highest quality classes „Esc” and „E” were produced in the autumn $(85.46 \%)$. The relative share of the low-class livers „TV" and „C", as well as the proportion of culled produce was the highest in the spring, compared to other seasons.

The reasons for the lower yield of liver, especially of the „Esc" and „E” classes in the summer and partially towards the end of the spring season, could be related to the high ambient temperature, including the environment of the duck fattening facilities, despite the measures taken for keeping it normal. According to published research data, it is one of the main factors for the insufficient fulfillment of ducks' and geese's potential with regard to liver steatosis, as a result of disrupting the thermoregulation and respiratory processes within their bodies (Guémené et al., 2001; Molee et al., 2005; Guémené et al., 2006).

The excessively long period of forced fattening (over two weeks) conceals great risks related to the enlarged liver and fat content. It could lead to a disruption in the hepatocytes' function due to a reduced blood flow to the liver and other physiological effects (Bogin et al., 1984; Bengone-Ndong, 1996; Skipon, 2013). 
Similar data were reported in the histological studies of Tanchev \& Bochukov (1993) on livers of Pekin $\times$ Muscovy ducks after 14-day force feeding outlining that the most substantial fat infiltration occurred during the last 4 days. The authors concluded that fattening longer than 14 days was not economically justified not only due to increased corn expenses, but also with regard to deteriorating the quality of the liver. A similar correlation between the fattening period and the severity of the changes in the histostructure of goose liver was reported by Dzhurov \& Kostadinov (1981).

The data from our study correspond to the changes in the goose liver's histostructure found via computer tomography and histological examination, after 18 days of force-feeding (Locsmandi et al., 2007).

Through of the morphological and functional alterations occurring during force-feeding ( 3 cycles of 2 weeks and a 4-week break between them) some authors proved that the enlargement and changes in the histostructure of the duck liver were reversible (Benard et al., 2006).

\section{CONCLUSION}

Foie gras of the of the „Esc” quality class was characterised with predomination of hepatocytes which contained one large fat drop each in their cytoplasm. The cellular boundaries were preserved in most cases, yet merging of the forms of some hepatocytes was observed as well. The cell nuclei were missing. In the „E” quality class there were predominantly hepatocytes with large-drop fatty infiltration. Nevertheless, the cellular boundaries remained intact, and the nuclei had a spherical shape. For the „AD” class, the glandular tubules, whose hepatocytes contain fat drops of various sizes in their cytoplasm, were most commonly observed.

In the "TV" class there were two types of glandular tubules with small- and medium-drop fat infiltration. In some cases, large-drop fat infiltration was observed as well. The connective tissue between the glandular tubules was preserved without fattening of its cells. In the „C" class there was primarily small-drop cell infiltration in the cytoplasm of most hepatocytes. Although rarely, there were single cases of medium to large hepatocytes, which have preserved their cellular boundaries.

\section{REFERENCES}

Anonymous, 2015. Bulletin No. 294-VI. Agrostatistics, Ministry of Agriculture and Food, Bulgaria (BG).

Baudonnet-Lenfant, C., 1993. Facteurs de variation de la composition biochimique et de la qualité technologique des foies gras de canards. Thèse de Doctorat, Institut National Polytechnique, Toulouse, France, $\mathrm{p}$. 175.

Benard, G., T. Bengone, D. Prehn, S. Durand, C. Labie \& P. Benard, 2006. Contribution à l' étude de la physiology du canard en gavage: étude de la stéatose hépatique. $B u$ lletin de l'Académie Vétérinaire de France, 159, 43-51.

Bengone-Ndong, T., 1996. Contribution à l'étude des conséquences du gavage de canards sur le devenir des xénobiotiques. Thèse de Doctorat, Institut National Polytechnique, Toulouse, France, p. 56.

Bogin, E., Y. Avidar, M. Merom, B. A. Israeli, M. Malkinson, S. Soback \& Y. Kudler, 1984. Biochemical changes associated with fatty liver in geese. Avian Pathology, 13, 683-701.

Bonnefont, C., R. El Kouba, M. Travanca, S. Dejean, A. Vignal, M. Bouillier-Oudot, N. Marty-Gasset, E. Labarthe, H. Manse, J. Arroyo, J.-P. Dubois, D. Viala Didier, C. Chambon \& C. Molette, 2015. Effet du 
type de maïs en gavage et de la durée de jeune avant abattage sur les caractéristiques biochimiques et génomiques fonctionnelles du foie gras chez le canard mulard. $11^{\text {èmes }}$ Journées de la Recherche Avicole et Palmipèdes à Foie Gras, Tours, INRA-ITAVI, p. 5.

Dzhurov, A. \& K. Kostadinov, 1981. Histological changes in the liver of Benkovska breed geese during the fattening period. $\mathrm{Ve}$ terinary Science (Sofia), 18, 76-83 (BG).

Gabarrou, J. F., S. M. Ralichon, G. Guy \& J. C. Blum, 1996. Hybrid ducks overfed with boiled corn develop an acute hepatic steatosis with decreased choline and polyunsaturated fatty acid level in phospholipids. INRA Reproduction Nutrition Development, 36, 473-484.

Gontier, K., J-M. André, M-D. Bernadet, K. Ricaud \& S. Davail, 2013. Insulin effect on lipogenesis and fat distribution in three genotypes of ducks during overfeeding. Comparative Biochemistry and Physiology Part A, 164, 499-505.

Guémené, D., G. Guy, J. Noirault, M. GarreauMills, P. Gouraud \& J. M. Faure, 2001. Force-feeding procedures and physiological indicators of stress in male mule ducks. British Poultry Science, 42, 650-657.

Guémené, D., G. Guy, J. Noirault, N. Destombes, J. M. Faure, 2006. Rearing conditions during the forcefeeding period in male mule ducks and their impact upon stress and welfare. Animal Research, 5, 443-458.

Guy G., D. Hermier, S. Davail, M. Bely, J. M. André \& R. Hoo-Paris, 1999. Meat production and force-feeding ability of different types of ducks. In: Proceedings of the $1^{\text {st }}$ World Waterfowl Conference, 1-4.12. 99, Taichung, Taiwan, pp. 462-468.

Molee, W., M. Bouillier-Oudot, A. Auvergne \& R. Babilé, 2005. Changes in lipid composition of hepatocyte plasma membrane induced by overfeeding in duck. Comparative Biochemistry and Physiology, B141, 437-444.
Locsmandi, L., G. Hegedus, G. Andrssy-Baka, F. Bogenfurst \& R. Romvari, 2007. Following the goose liver development by means of cross-sectional digital imaging, liver histology and blood biochemical parameters. Acta Biologica Hungarica, 58, 1-4.

Rousselot-Paillet, D., G. Guy, D. Gourichon, N. Sellier, J. C. Blum, 1992. Influence des conditions d'abattage et de réfrigeration sur la qualité des foies gras d'oie. INRA Productions Animales, 5, 167-172.

Skippon, W., 2013. The animal health and welfare consequences of foie gras production. Canadian Veterinary Journal, 54, 403-404.

Tanchev, S. \& A. Bochukov, 1993. Liver growth and histostructure of gavaged Pekin/Muscovy duck hybrids. Genetics and Selection, 26, 222-229 (BG).

Theron, L., M. Cullere, M. Bouillier-Oudot, H. Manse, A. Dalle Zotte, C. Molette, X. Fernandez \& Z. G. Vitezica, 2012. Modeling the relationships between quality and biochemical composition of fatty liver in mule ducks. Journal of Animal Science, 90, 3312-3317.

Paper received 21.04.2016; accepted for publication 10.06.2016

\section{Correspondence:}

Assoc. Prof. Vasko Gerzilov

Department of Animal Science,

Faculty of Agronomy, Agricultural University, Plovdiv, Bulgaria,

e-mail: v_gerzilov@abv.bg 